\title{
Innibition of carnitine palmitoyltransferase leads to induction of 3-hydroxymethylglutaryl coenzyme A reductase activity in rat liver
}

\author{
Hans Jansen ${ }^{1,}$, Nicoline Hoogerbrugge Van der Linden ${ }^{2}$ and Willem $C$. Hülsmann ${ }^{3}$

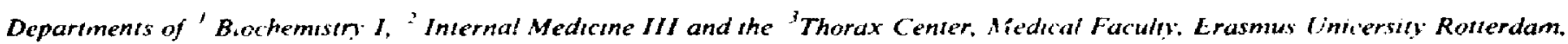

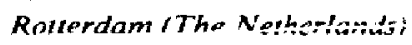 \\ (Received 7 July 1989) \\ (Revised manuscript received 12 March 1990)
}

Key words: Cholesterol synthesis: Regulation: HMG-CoA ieductase: Fatty acid oxidation: (Rat liver)

\begin{abstract}
The relation between carnitine palmitoyltransferase (CPT) activity and 3-hydroxy-3-methylglutaryl coenzyme A (HMG-CoA) reductase activity was investigated. Rats were treated with aminocarnitine or 1-carnitine overnight. In rats, in which CPT activity was inhibited by aminocarnitine, plasma and hepatic triacylglycerol contents were increased 5 - to 6-fold. The plasma cholesterol concentration was unchanged, while the hepatic cholesterol content was lowered ( $-16 \%)$. Hepatic cholesterol synthesis, determined by following the incorporation of ${ }^{14} \mathrm{C}$-acetate and ${ }^{3} \mathrm{H}_{2} \mathrm{O}$ into digitonin-precipitable sterols, in liver slices was increased 5- to 7-fold. HMG-CoA reductase activity in liver microsomes was increased to the same extent.
\end{abstract}

3-Hydroxy-3-methylglutaryl coenzyme A (HMGCoA) reductase (EC 1.1.1.34) is the rate-limiting step enzyme in cholesterol synthesis $[1,2]$. The asnount of enzyme and its activity is controlled by several mechanisms at different levels [3]. Fatty acid-oxidation and -esterification and cholesterol synthesis are closely related by different mechanisms [4-6]. This is of interest as several hypolipidemic drugs are krown to affect fatty acid metabolism. Fibrates, for example, induce proliferation to peroxisomes and stimulate peroxisomal fatty acid oxidation $[7,8]$. Conversely, it has been reported that the HMG-CoA reductase inhibitor, lovastatin, induces carnitine palmitoyltransferase activity [9]. During studies on the lipid effects of adrenoceptor-blockers in hamsters, we found that the cholesterol content of plasma and liver were largely diminished during selective $\alpha_{1}$-blockade [10]. The lowering of the cholesterc] tevel couid he exnlained by a diminished rate of hepatic chole,ter ! synthesis. However, since $\alpha_{1}$-blockade also decreases hepatic (and plasma) triacylglycerols, additional mechanisms must he operative. In preliminary experiments, we found that $\alpha_{1}$-bluckade increased carnitine palmitoyltransferase $(C, P T)$ activity (Jansen,

Correspendence: H. Jansen, Department of Biochemistry 1 , Medical Faculty, Erasmus University Rotterdam, P.O.B. 1738, 3000 UR Rotterdam, The Netherlards.
H., unpublished data), which could lead to a more effective fatty acid oxidation. Indeed, Woodside and Swindell [11] demonstrated, that $\alpha_{1}$-blockade stimulates ketone body formation in rats, indicating an increased fatty acid oxidation. We wondered whether the effects of the $\alpha$-blocker on cholesterol synthesis and CPT activity could be metabolically linked. Therefore. we investigated whether inhibition of CPT activity may direcrly affect cholesterol synthesis and, more specifically, HMG-CoA reductase activity.

Male Wistar rats were used (225-260 g). They had free access to food and tap water unless noted otherwise. 4 weeks before use. they were placed on a vegatarian diet composed of grains, maize, (s nflower) seeds and dried vegetables (rabbit chow, Holland Diervoeders, Hilversum. The Netherlands). At the end of the day before use, the rats were i.p. injected with aminocarnitine ( $15 \mathrm{mg} / \mathrm{kg}$ bodyweight), an inhibitor of the carnitine palmitoyltransferase (CPT) reaction [12], Lcarnitine $(140 \mathrm{mg} / \mathrm{kg}$ body weight) or $0.15 \mathrm{M} \mathrm{NaCl}$ (Controls). The rats were fasted overnight and killed the next morning by decapitation. Cholesterol synthesis was determined by following the incorporation of ${ }^{14} \mathrm{C}$-acetate and ${ }^{3} \mathrm{H}_{2} \mathrm{O}$ into digitonin-precipitable sterols. Part of the livers (about $200 \mathrm{mg}$ ) was immediately incubated for 90 min at $37^{\circ} \mathrm{C}$ in a glass counting vial under an $\mathrm{O}_{2} / \mathrm{CO}_{2}$ (95/5\%) atmosphere in $2 \mathrm{mi} \mathrm{Krebs-Ringer} \mathrm{bicarbonate}$ buffer (pH 7.4) containing $11 \mathrm{mM}$ glucose and $2.5 \mathrm{mCi}$ 
${ }^{3} \mathrm{H}_{2} \mathrm{O}$. The formed, ${ }^{3} \mathrm{H}$-labelled, cholesterol was isolated as digitonin-precipitable sterols (as described in Ref. 13). In some experiments the ${ }^{3} \mathrm{H}_{2} \mathrm{O}$ was replaced by 1 $\mathrm{mM}{ }^{14} \mathrm{C}$-acetate $(1 \mathrm{Ci} / \mathrm{mol})$. In these experiments, ${ }^{14} \mathrm{CC}_{2}$ generated was trapped in a plastic reaction vessel containing filter paper soxked with $100 \mu 1$ Hyamine hydroxide (Packard, Warrenville, U.S.A.). The ${ }^{14} \mathrm{C}$-acetate incorporated into cholesterol was determined as digitonin-precipitable sterols or, in some experiments. non-esterified cholesterol and cholesterol-esters were determined separately. In these experiments the lipids were extracted from the incubation medium and cholesterol was separated from cholesterol ester by thin-layer chromatography [14]. The contribution of ${ }^{14} \mathrm{C}$-fatty acids to the radioactivity in the cholesterol esters was determined in the livers of rats treated with either $0.15 \mathrm{M} \mathrm{NaCl,} \mathrm{aminocarnitine} \mathrm{or} \mathrm{carnitıne} \mathrm{after}$ saponification of the cholesterol esters and separation of the cholesterol and fatty acids by thin-layer chromatography. It appeared that ${ }^{14} \mathrm{C}$-fatty acids contributed for $43 \pm 2 \%$ (mean $\pm S . E ., n=18$ ) to the radioactivity in the cholesterol esters. There was no significant difference in this percentage between the different treatment groups. For each animal the percentage of de novo synthesized cholesterol which was esterified was calculated. HMG-CoA reductase activity was determined in liver microsomes after dephosphorylation. as described by Balasubramaniam et al. [15]. Acyl-CoA cholesterol acyltransferase (ACAT) activity was determined in liver homogenates as described by Erickson and Cooper [16]. Liver and plasma lipids and plasma 3-hydroxybutyrate were determined with enzymatic methods (Testkit combinations (Boehringer Mannheim. Mannheim, F.R.G.). All results were expressed as means \pm S.E. The statistical significance of differences be'ween groups was evaluated with the unpaired Student's $t$-test.

The bodyweights of the rats was not affected by either treatment, controls $235 \pm 6 \mathrm{~g}(n=12)$, carnitine rats $234 \pm 5(n=12)$ á 1 aminocarnitine ra.s $234 \pm 4 g$ $(n=12)$. The liver weig, was increased by the aminocarnitine treatment $(8.6 \pm 0.2 \mathrm{~g}$ after aminocarnitine treatment, $7.4 \pm 0.2 \mathrm{~g}$ in the controls and in the carnitine-treated animals, $n=12$ in all groups, $P<0.001$ ).

The triacylglycerol content of the livers was greatly increased by the aminocarnitine treatment (Table I), so that the part of the increased liver weight was due to accumulated triacylglycerols. Plasma triacylglycerols were aiso elevated in the aminocarnitine rats. Plasma choksterol was not affected, liver cholesterol was, however, lowered $(-16 \%)$ in the aminocarnitine rats (Table I).

Cholesterol synthesis in the liver, assessed by following the incorporation of ${ }^{3} \mathrm{H}_{2} \mathrm{O}$ as well as ${ }^{14} \mathrm{C}$-acetate into cholesterol by liver slices, was in the aminocarnitine-treated animals increased 5-7 fold $(P<0.005)$ in
TABLE I

Cffects of carnutine and ammo-cumbere un plasma and liver lipids

Contents of triacylglycerol and sholesterol in the livers of rats treated with either $0.15 \mathrm{M} \mathrm{NaCl}$. 1-carnitine or aminocarnitine. The data of the plasma are expressed in $\mathrm{mM}$. of the liver total hepatic content in $\mu \mathrm{mol}$ is given. The plasma alues are the means \pm S.E. of 12 rats in each group. the liver valus of 6 rats in each group

\begin{tabular}{|c|c|c|c|c|}
\hline \multirow[t]{2}{*}{ Treatment } & \multicolumn{2}{|c|}{ Triacylglycerol } & \multicolumn{2}{|c|}{ Cholestero. } \\
\hline & $\begin{array}{l}\text { Plasma } \\
(\mathrm{mM})\end{array}$ & $\begin{array}{l}\text { Liver } \\
\text { ( } \mu \mathrm{mo}^{*}\end{array}$ & prasma & $\begin{array}{l}\text { Liver } \\
\because\end{array}$ \\
\hline $0.15 \mathrm{M} \mathrm{NaCl}$ & $1.5 \pm 0.2$ & $208 \pm 29$ & $2.6 \pm 0.1$ & $\overline{96 \pm 4}$ \\
\hline Carnitine & $1.6 \pm 0.1$ & $167 \pm 25$ & $2.7 \pm 0.1$ & $94 \pm 6$ \\
\hline Aminocarnitine & $60 \pm 1.1 *$ & $847 \pm 95 * *$ & $2.7 \pm 0.1$ & $81 \pm 4$ \\
\hline
\end{tabular}

Means \pm S.E. * denotes a statistically significant difference from the $0.15 \mathrm{M} \mathrm{NaCl}$ group with $P<0.025 * * P<0.001$

comparison to the other groups (Table II). HMG-CoA reductase activity was significantly $(P<0.001)$ elevated to the same extent as overall cholesterol synthesis ( 657 $+61 \mathrm{pmol} / \mathrm{mg}$ protein in the aminocarnitine rats $(n=$ 8). $119 \pm 14 \mathrm{pmol} / \mathrm{mg}$ protein in the controls $(n=6)$ and $176 \pm 30 \mathrm{pmol} / \mathrm{mg}$ protein in the carnitine rats $(n=6)$ (Fig. 1).

Thest results show that impairment of fatty acid oxidation at tue level CPT, greaty stimulates the cholesterol-synthesizing capacity of the liver. The underlying mechanism is not clear. One possibility is that by inhibition of the oxidation fatty acid derivatives (acyl-CoA and acylcarnitine) accumulate and become more esterified. In this way, besides triacylglycerol formation. cholesterol ester formation may be increased. The pool of HMG-COA reducti-c reslating nonesterified cholesterol may be lowered and the suppression of HMG-CoA reductase relievad. In concurrence with this idea. it appeared that in vitro in the aminocarnitine-treated rats. a much laiger part of the de novo-synthesized cholesterol was esterified than in the

\section{TABLE II}

Effect of carntine and amino-carmitne on hepatic cholesterol symthess Cholesterol synthesis was determined in liver slices of rats treated with either $0.15 \mathrm{M} \mathrm{NaCl}$. 1-carnitine or aminocarn tine ${ }^{14} \mathrm{C}$-Actetate and ${ }^{3} \mathrm{H}_{2} \mathrm{O}$ incorporated into digitoniri-precipitable sterols was de termined in different animals. The data are expressed in $\mathrm{dpm} / \mathrm{g}$ liver (means \pm S.E.)

\begin{tabular}{lcl}
\hline Treatment & \multicolumn{2}{c}{ dpm incorporated into cholesterol } \\
\hline 0.15 M NaCl & \multicolumn{1}{c}{$\mathrm{C}$-acetate } & ${ }^{3} \mathrm{H}_{2} \mathrm{O}$ \\
Sarnitine & $4660 \pm 490(6)$ & $200 \pm 15(4)$ \\
Aminocarnitine & $23510 \pm 2030(6) *$ & $1470 \pm 150(4)^{*}$ \\
\hline
\end{tabular}

* denotes a statistically significant difference from the 0.15.M NaCl group with $P<0.005$. n.d. not determined 


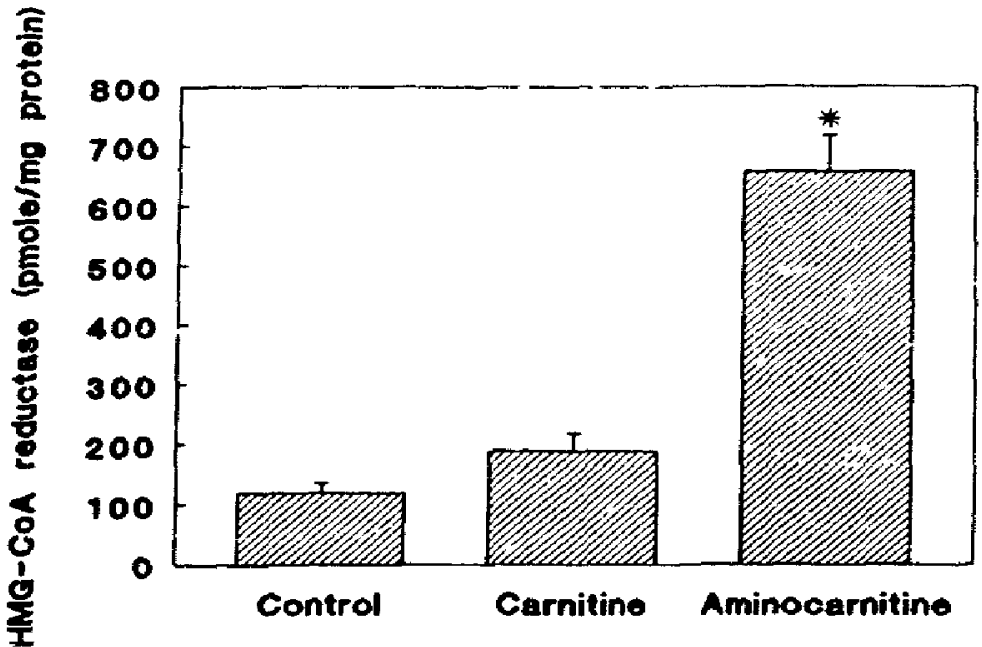

Fig. 1. Effects of aminocarnitine and carnitine administration on HMG-COA reductase activity in rat liver. HMG-CoA reductase it hepatic microsomes was determined as described under Methods (and in Ref. 15). The activity of HMG-CoA reductase is expressed in pmol/min per mg microsomal protein (six controls and carnitinetreated, eight rats treated with aminocarnitine). Given are means $\pm S$.E

* denotes a significant difference from both other groups $(P<0.001)$.

other groups (Table III). The enhanced esterification of cholesterol could not be explained by activation of the acyl-CoA cholesterol acyltransferase, as the activity of this enzyme was not significantly affected by the treatment with aminocarnitine (Table II). Rather, in vitro, the ACAT activity tended to be lower in the aminocarnitine group in comparison to the other, especially the carnitine-treated, animals. Since endogenous cholesterol serves as a substrate for the ACAT reaction, in vitro differences in cellular cholesteroi content may be reflected in the measured activity. The relation between fatty acid oxidation and triacylglycerol and cholesterol synthesis has been demonstrated in several

\section{TABLE III}

Effect of carnitine and aminocarnitine on the formation of cholesterolesters in rat liver

The cholesterol esterification in the livers of rats treated with either $0.15 \mathrm{M} \mathrm{NaCl}, 1$-carnitine or aminocarnitine was established by measuring the ACAT activity and by determination of the percentage of the total de novo synthesized cholesterol which was esterified in vitro. Cholesterol synthesis was followed by measuring ${ }^{14} \mathrm{C}$-acetate incorporation. Data are ex; resced as mean \pm S.E. (ACAT activity: $100 \%=55.7$ mU.'g liver)

\begin{tabular}{lll}
\hline Treatment & $\begin{array}{l}\text { ACAT activity } \\
(9 \text { of control) }\end{array}$ & $\begin{array}{l}\text { T4-cholesterol esterified } \\
(\mathcal{E}:=\text { otal synthesized })\end{array}$ \\
\hline $0.15 \mathrm{M} \mathrm{NaCl}(6)$ & $100 \pm 5$ & $16.3 \pm j .7$ \\
Carnitine (6) & $108 \pm 8$ & $13.1 \pm 3.1$ \\
Amino-carnitine (6) & $8^{\prime} \pm 9$ & $38.0 \pm 7.1 *$ \\
\hline
\end{tabular}

- denotes a statistically significant difference from the other group: $P<0.001$ ways. An increased supply of fatty acids leads to stimulation of the esterification into triacylglycerol and cholesterol esters and induction of lipogenic enzyme activities [4]. The enhanced esterification of cholesterol may result in a lowering of the regulating cellula- nonesterified cholesterol pool and to stimulation of cholesterol synthesis [4]. Also, a change in the partition of fatty acids from taty acid oxidation to esterification, as found in the obese Zucker rat, is accompanied by enhanced triacylglycerol and cholesterol synthesis [5]. Conversely, inhibition of triacyiglycerol synthesis lear's to an increased conversion of fatty acids to ketone bodies [6]. Our results fit well in the close relation between fatty acia oxidation and lipogenesis. The increased HMG-CoA reductase activity after aminocarnitine did not result in an elevation of liver or plasma cholesterol. This is probably due to a deficit of substrate (acetyl-CoA) for cholesterol synthesis during aminocarnitine treatment in situ, as reflected in a $50 \%$ decrease in the plasma ketone body ( $\beta$-hydroxybutyric acid) concentration after aminocarnitine treatment (Controls $1.28 \pm 0.08 \mathrm{mM}$, aminocarnitine $0.66 \pm 0.03$ $\mathrm{mM}$, carnitine $1.58 \pm 0.16$ (means \pm S.E., $n=8$ for all groups)) [9]. In contrast, if determined in vitro, overall cholesterol synthesis was increased in the livers of aminocarnitine-treated rats. The availability of acetylCoA under these conditions was not limited as glucose (11 $\mathrm{mM}$ ) was added to the incubation mixture. This means that, in vivo, under conditions where substrate supply is sufficient, lowering of CPT activity may lead to cholesterol accumulation. The same holds for conditions that cholestercl is available from a source other than de novo synthesis, such as the diet. In this respect, it is of interest to note that during the feeding of a cholesterol-enriched diet of golden hamster, CPT activity was found to be depressed (Jansen, H., unpublished data). This may, in the light of our present results, contribute to the development of hypercholesterolemia in these animals. Our results demonstrate that the cholesterol synthesizing capacity and CPT activity and closely metabolically interrelated. This is of importance in evaluating the effect of diets and drugs on cholesterol homeostasis.

Sigma Tau (Rome) is acknowledged for financial help, Dr. F. Maccari for the gift of aminocarnitine and Prof. H.R. Scholte for helpful discussions. Ina Kalkman, Mrs. Lilian Weeks, Mrs. Nicole Wouters and Mrs. Elly de Wit have contributed with excellent technica! assistance.

\section{References}

1 White, L.W. and Rudney, H. (1970) Biocheristry 9, 2725-2731. 2 Shapiro, D.J. and Rodwell, V.W. (1971) J. Biol. Chem. 246, $3210-3216$. 
3 Beg, Z.H., Stonik, J.A. and Brewer, Jr, H.B. (1987) Metabolism 39. $900-917$.

4 Salam, W.H., Wilcox, H.G.. Cagen, L.M. and Heimberg. $M$ (1989) Biochem. I 258, 563-568.

5 A ain. M.J., Fukuda, N., Chao, F.F., Yamamoto, M. and Ontko, J.A. (1985) J. Biol. Chem. 260, 174-181.

6 Yanamoto, M., Fukuda, N., Triscari, J., Sullivan, A.C. and Ontko, J.A. (1985) J. Lipid Res. 26, 1196-1204.

7 Reddy, J.K. and Krishnakantha, I.P. (1975) Science 190, 787-789.

8 Lazarow, P.B. and De Duve, C. (1976) Proc. Natl. Acad. Sci. USA 73, 2043-2046.

9 Cook, G.A., Khan, B. and Heimberg, M. (1988) Biochem. Biophys. Res. Comnun. 150, 1077-1082.
10 Jansen. H., Lammers, R., Baggen, M.G.A and Birkenhäger. J.C. (1989) J. Cardiovasc. Cardiol. 13 (suppl. 2) S5-S10.

11 Woodside, W.F. and Swindell. A.C. (1987) J. Cardiovasc. Pha:macol. 10 (suppl. 9), 27-34.

12 Jenkins, D.L. and Griffith, O.W (1985) J. Biol. Chem. 260. 14748-14755.

13 Spady. D.K. and Dietschy, J.M. (1983) J. Lipid Res. 24, 303-315. 14 Jansen, H. (1985) Biochem. Biophys. Res. Commun. 131, 571-578.

15 Balusubramaniam, S., Goldstein. J.L.. Faust, J.R. and Brown, M.S. (1976) Proc. Natl. Acad. Scj. USA 73. 2564-2568.

16 Erickson, S.K. and Cooper, A.D. (1980) Metabolism 29, $991-996$. 